\title{
CRESCIMENTO IN VITRO DE AMOREIRA-PRETA: EFEITO DE REGULADORES DE CRESCIMENTO E DA CULTIVAR
}

\author{
In vitro blackberry growing: effect of growth regulators and cultivar
}

Fabíola Villa', Moacir Pasqual², Franscinely Aparecida de Assis ${ }^{3}$, Leila Aparecida Salles Pio ${ }^{1}$, Gleice Aparecida de Assis ${ }^{4}$

\section{RESUMO}

Desenvolveu-se, este trabalho, no intuito de aprimorar técnicas de propagação in vitro de amoreira-preta. Testou-se em um experimento a influência de cinco diferentes concentrações de ANA $\left(0 ; 0,1 ; 0,5 ; 1,0\right.$ e $\left.1,5 \mathrm{mg} \mathrm{L}^{-1}\right)$ e cinco de GA $\left(0 ; 2 ; 4 ; 6\right.$ e $\left.8 \mathrm{mg} \mathrm{L}^{-1}\right)$, adicionadas ao meio de cultura MS, sob a amoreira-preta cultivar Ébano e; num segundo experimento testaram-se seis diferentes concentrações de ANA $\left(0 ; 0,1 ; 0,5 ; 1,0 ; 1,5\right.$ e $\left.2,0 \mathrm{mg} \mathrm{L}^{-1}\right)$ e duas cultivares de amoreira-preta (Tupy e Brazos), no crescimento in vitro de plântulas. Segmentos nodais com $2 \mathrm{~cm}$, de plântulas preestabelecidas in vitro, foram excisadas e inoculadas, em meio MS. O experimento foi inteiramente casualisado, utilizando-se três explantes por repetição e quatro repetições por tratamento. $\mathrm{O} \mathrm{pH}$ do meio foi ajustado para 5,8 depois da adição de $6 \mathrm{~g} \mathrm{~L}^{-1}$ de ágar e $30 \mathrm{~g} \mathrm{~L}^{-1}$ de sacarose, ocorrendo depois a autoclavagem a $121^{\circ} \mathrm{C}$ e 1 atm por 20 minutos. Após a inoculação, os tubos de ensaio foram mantidos por 60 dias, em sala de crescimento a $27 \pm 1^{\circ} \mathrm{C}$, irradiância de $35 \mathrm{mmol} \cdot \mathrm{m}^{-2} \cdot \mathrm{s}^{-1} \mathrm{e}$ fotoperíodo de 16 horas, avaliando-se assim o número de folhas, número de raízes, comprimento da maior raiz, comprimento da parte aérea, peso da matéria fresca e seca da parte aérea. Altas concentrações de $\mathrm{GA}_{3}$ associadas a baixas de ANA promoveram maior comprimento da parte aérea da amoreira-preta, cultivar Ébano. Maior comprimento da parte aérea de 'Brazos' foi verificado na presença de $1,0 \mathrm{mg} \mathrm{L}^{-1}$ de ANA. Verificou-se surgimento de calos na cultivar Ébano em todas as concentrações de $\mathrm{GA}_{3}$ associadas a 0,5-1,5 $\mathrm{mg} \mathrm{L}^{-1}$ de ANA e nas cultivares Tupy e Brazos em todas as concentrações de ANA. Melhores resultados na micropropagação da amoreira-preta cultivares Tupy e Ébano foram obtidos com a adição de $1,0 \mathrm{mg} \mathrm{L}^{-1}$ de ANA e melhores resultados no enraizamento da amoreira-preta cultivar Ébano foram obtidos com baixas concentrações de ANA e na ausência de $\mathrm{GA}_{3}$.

Termos para indexação: Meio de cultura MS, ANA, GA, Rubus spp., micropropagação.

\begin{abstract}
This work was developed with the aim of improving technics of in vitro propagation of blackberry. So, one tested in an experiment the influence of five different ANA concentrations $\left(0 ; 0,1 ; 0,5 ; 1,0\right.$ and $\left.1,5 \mathrm{mg} \mathrm{L}^{-1}\right)$ and five $\mathrm{AG}_{3}(0 ; 2,0 ; 4,0 ; 6,0$ and 8,0 $\mathrm{mg} \mathrm{L}^{-1}$ ), added to the culture medium MS, to the blackberry cv. Ebano and; in a second experiment was tested six different ANA concentrations $\left(0 ; 0,1 ; 0,5 ; 1,0 ; 1,5\right.$ and $\left.2,0 \mathrm{mg} \mathrm{L}^{-1}\right)$ and two blackberry cv. (Tupy and Brazos), in vitro plants growing. Nodal segments with $2 \mathrm{~cm}$, of in vitro plants, were excised and inoculated, in a MS culture medium. The experiment was entirely randomized blocks using three explants by repetition and four repetitions per treatment. The $\mathrm{pH}$ of the culture medium was adjusted for 5.8 after the addition of $6 \mathrm{~g} \mathrm{~L} \mathrm{~L}^{-1}$ agar and $30 \mathrm{~g} \mathrm{~L}^{-1}$ sucrose, happening sterilization later at $121^{\circ} \mathrm{C}$ and $1 \mathrm{~atm}$ per 20 minutes. After the inoculation, the tubes were maintained by 60 days, in growth room at $27 \pm 1^{\circ} \mathrm{C}$, irradiance of $35 \mathrm{~mol} . \mathrm{m}^{-2} \cdot \mathrm{s}^{-1}$ and photoperiod of 16 hours, being evaluated the number of leaves, number of roots, length of the largest root, length of the aerial part, dry weight of the fresh and dry matter of the aerial part. High concentrations of $\mathrm{AG}_{3}$ associated to low concentrations of ANA promoted larger length of the aerial part of the blackberry cv. Ebano. Larger length of the aerial part of 'Brazos' was verified in the presence of $1.0 \mathrm{mg} \mathrm{L}^{-1}$ ANA. Appearance of callus was verified in blackberry cv. Ebano in all the $\mathrm{AG}_{3}$ concentrations associated to $0.5-1.5 \mathrm{mg} \mathrm{L}^{-1} \mathrm{ANA}$ and in cv. Tupy and Brazos in all the ANA concentrations. Better results in the blackberry micropropagation cv. Tupy and Ebano were obtained with the addition of $1.0 \mathrm{mg} \mathrm{L}^{-1}$ ANA and better results in the blackberry rooting cv. Ebano were obtained with low ANA concentrations and $\mathrm{AG}_{3}$ absence.
\end{abstract}

Index terms: MS culture medium, growth regulators, micropropagation.

(Recebido em 22 de junho de 2006 e aprovado em 16 de julho de 2007)

\section{INTRODUÇÃO}

A amora-preta (Rubus spp.) é uma frutífera de clima temperado pertencente à família Rosaceae, que contém segundo Ying et al. (1990), aproximadamente 740 espécies. Estima-se que a área cultivada no Brasil esteja ao redor de 250 hectares (RASEIRA, 2004), sendo o Rio Grande do Sul o principal produtor, seguido de Santa Catarina, Paraná,

\footnotetext{
1Pós-Doutorandas em Fitotecnia - Departamento de Agricultura/DAG - Universidade Federal de Lavras/UFLA - Cx. P. 3037 - $37200-000$ - Lavras, MG fvilla2003@libero.it; leilapio@ufla.br

2Doutor, Professor Titular - Departamento de Agricultura/DAG - Universidade Federal de Lavras/UFLA - Cx. P. 3037 - $37200-000$ - Lavras, MG mpasqual@ufla.br

${ }^{3}$ Mestranda em Entomologia - Departamento de Entomologia/DEN - Universidade Federal de Lavras/UFLA - Cx. P. 3037 - $37200-000$ - Lavras, MG franscinely.agronomia@ufla.br

${ }^{4}$ Engenheira Agrônoma - Departamento de Agricultura/DAG - Universidade Federal de Lavras/UFLA - Cx. P. 3037 - $37200-000$ - Lavras, MG
} 
São Paulo e Sul de Minas Gerais (ANTUNES \& RASEIRA, 2004).

A micropropagação é considerada a principal técnica de cultura de tecidos, em termos de potencial prático de utilização na agricultura, produzindo mudas com características genéticas idênticas às da planta-matriz, permitindo a clonagem de genótipos selecionados e de alta qualidade genética. Além disso, todas as mudas produzidas são livres de vírus, uniformes e obtidas em um curto espaço de tempo; otimizando dessa forma a exploração de pequenos frutos.

O estudo de propagação in vitro de amoreira-preta é de grande relevância, pois há poucas pesquisas aprofundadas nesse tema, no Brasil, e essa é uma espécie importante, principalmente para os estados produtores do país (AUGUSTO, 2001). Sobretudo, são poucos os trabalhos específicos sobre as cultivares existentes no Brasil. Segundo Mokhammed \& Butenko (1998), a regeneração é bastante dependente do genótipo de Rubus utilizado e um método desenvolvido para uma cultivar pode apresentar resultados distintos em outras cultivares.

Os reguladores de crescimento são substâncias que controlam o desenvolvimento de raízes adventícias (TAIZ \& ZEIGER, 1991), sendo as auxinas os únicos reguladores de crescimento que promovem a expansão celular e as giberelinas promovem o alongamento celular e ativação de enzimas hidrolíticas. São utilizadas para promover o crescimento em extensão de ramos e quebra de dormência de gemas e sementes (PASQUAL, 2000).

Utilizando-se explantes de amoreira-preta cv. Ébano acrescido com $0,1 \mathrm{mg} \mathrm{L}^{-1}$ de ácido indolbutírico ou ácido naftalenoacético ao meio MS, Pasqual et al. (1991) obtiveram bom enraizamento de mudas sem ocorrer à formação de calo.

Objetivou-se avaliar o efeito dos reguladores de crescimento ANA e $\mathrm{GA}_{3}$ na micropropagação de amoreirapreta cvs. Ébano, Tupy e Brazos.

\section{MATERIALE MÉTODOS}

Segmentos nodais com cerca de $2 \mathrm{~cm}$ de comprimento, oriundos de plântulas preestabelecidas in vitro foram excisados e introduzidos em tubos de ensaio contendo $15 \mathrm{~mL}$ do meio de cultura. $\mathrm{O}$ primeiro experimento consistiu em cinco diferentes concentrações de ANA $(0 ; 0,1 ; 0,5 ; 1,0$ e $\left.1,5 \mathrm{mg} \mathrm{L}^{-1}\right)$ e cinco de $\mathrm{GA}_{3}\left(0 ; 2,0 ; 4,0 ; 6,0\right.$ e $\left.8,0 \mathrm{mg} \mathrm{L}^{-1}\right)$, em todas as combinações possíveis, adicionadas ao meio de cultura MS (MURASHIGE \& SKOOG, 1962) e da amoreirapreta (Rubus spp.) cv. Ébano. O segundo experimento consistiu em seis diferentes concentrações de ANA $(0 ; 0,1$; 0,$5 ; 1,0 ; 1,5$ e 2,0 $\mathrm{mg} \mathrm{L}^{-1}$ ) e duas cultivares de amoreira-preta (Tupy e Brazos), em todas as combinações possíveis.
Os meios foram acrescidos de $30 \mathrm{~g} \mathrm{~L}^{-1}$ de sacarose, solidificados com $6 \mathrm{~g} \mathrm{~L}^{-1}$ de ágar e os $\mathrm{pH}$ ajustados para 5,8 , antes da autoclavagem a $121^{\circ} \mathrm{C}$ e $1 \mathrm{~atm}$ por 20 minutos. Posteriormente à inoculação, os tubos de ensaio foram transferidos para sala de crescimento a $25 \pm 2^{\circ} \mathrm{C}$, irradiância de $35 \mathrm{mmol} . \mathrm{m}^{-2} \cdot \mathrm{s}^{-1} \mathrm{e}$ fotoperíodo de 16 horas diárias, permanecendo nessas condições por 60 dias. O delineamento experimental utilizado foi inteiramente casualisado, utilizandose de quatro repetições com doze plântulas por tratamento.

Foram avaliados os números de folhas e de raízes, comprimento da maior raíz, comprimento da parte aérea, peso da matéria fresca e seca da parte aérea e peso da matéria fresca e seca de calos. Os dados foram analisados através do software Sisvar (FERREIRA, 2000), utilizando regressão polinomial para as variáveis ANA e $\mathrm{GA}_{3}$ e teste Scott-Knott para as cultivares de amoreira-preta.

\section{RESULTADOS E DISCUSSÕES}

No experimento 1, utilizando o teste $\mathrm{F}$ ao nível de 5\% de probabilidade, observou-se interação significativa para número de folhas, comprimento da parte aérea e peso da matéria fresca da parte aérea de plântulas de amoreirapreta. Para número de raízes e comprimento da maior raiz não foi verificada a interação significativa para os reguladores de crescimento. No experimento 2, utilizando o teste $\mathrm{F}$ ao nível de $5 \%$ de probabilidade, observou-se interação significativa para número de folhas, comprimento da parte aérea, peso da matéria fresca da parte aérea, número de raízes, peso da matéria fresca e seca de calos. Para peso da matéria seca da parte aérea não foi verificada a interação significativa para cultivares e ANA.

Com o incremento nas concentrações de ANA e na presença de $\mathrm{GA}_{3}$, houve um decréscimo no número de folhas de amoreira-preta cv. Ébano (Figura 1A). Maior número de folhas $(14,83)$ foi observado com $6,0 \mathrm{mg} \mathrm{L}^{-1} \mathrm{de} \mathrm{GA}_{3}$ e na ausência de ANA. Resultados antagônicos foram observados com outras cultivares de Rubus spp., onde Oliger et al. (1995) verificaram maior quantidade de folhas em microestacas nos tratamentos que continham uma combinação de $0,1 \mathrm{mg} \mathrm{L}^{-1} \mathrm{de}$ $\mathrm{GA}_{3}, 1,0 \mathrm{mg} \mathrm{L}^{-1}$ de AIB e $1,0 \mathrm{mg} \mathrm{L}^{-1}$ de BAP.

Como a relação do ANA para número de folhas da cultivar Ébano foi direta, pode-se inferir que o efeito desestimulante desse regulador no número de folhas continuaria para concentrações superiores a $1,5 \mathrm{mg} \mathrm{L}^{-1}$.

O mesmo foi verificado no experimento 2 para número de folhas das cultivares Tupy e Brazos, onde incremento nas concentrações de ANA, proporcionou um aumento no número de folhas até $1,0 \mathrm{mg} \mathrm{L}^{-1}$ de ANA, a partir do qual houve um decréscimo (Figura 1B). Maior número de folhas $(13,88)$ foi observado na cultivar Brazos com 1,0 mg L-1 de ANA. 


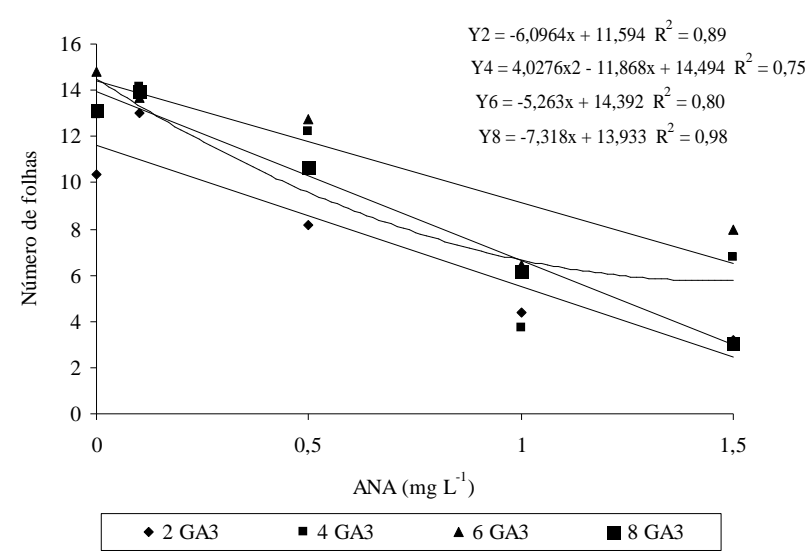

Figura 1 A - Número de folhas em plântulas de amoreirapreta cv. Ébano, com diferentes concentrações de ANA e $\mathrm{GA}_{3}$. UFLA, Lavras, MG, 2006.

As auxinas se constituem reguladores de crescimento responsáveis pela indução de raízes, o que se pode observar nesse trabalho. Maior número de raízes da cv. Ébano $(2,96)$ foi verificado com $0,1 \mathrm{mg} \mathrm{L}^{-1}$ de ANA (Figura 2A) e ausência de $\mathrm{GA}_{3}$ (Figura 2B). Aumentandose a concentração da auxina acima de $0,1 \mathrm{mg} \mathrm{L}^{-1}$ ocorreu uma diminuição de forma quadrática no número de raízes. Verificou-se também que o aumento das concentrações de $\mathrm{GA}_{3}$ induziu ao decréscimo no número de raízes formadas e no comprimento da maior raiz (Figuras 3A e 3B). Possivelmente, as concentrações utilizadas foram elevadas para amoreira-preta cv. Ébano, o que prejudicou seu enraizamento, sendo o conteúdo endógeno do explante suficiente para promover o enraizamento.

Para as cultivares Brazos e Tupy ocorreu um aumento de forma quadrática no número de raízes, sendo que maiores números $(3,47-2,79)$ foram verificados na cultivar Tupy com 0,5 e 1,0 $\mathrm{mg} \mathrm{L}^{-1}$ de ANA (Figura 2C), respectivamente. Pasqual et al. (1991) observaram uma perfeita formação de mudas com raízes abundantes e bem desenvolvidas em meio MS suplementado com $0,1 \mathrm{mg} \mathrm{L}^{-1}$ de ANA, enquanto que a $1,0 \mathrm{mg} \mathrm{L}^{-1}$ o desenvolvimento radicular foi prejudicado.

Fráguas (2003) trabalhando com figueira cv. 'Roxo de Valinhos' obteve resultado semelhante com o incremento de $0,5 \mathrm{mg} \mathrm{L}^{-1}$ de cinetina e ausência de $\mathrm{GA}_{3}$, sendo verificado média de 3,39 raízes na ausência desse regulador de crescimento e 2,2 raízes na presença de cinetina.

Kochba et al. (1974) citam que a presença de ácido giberélico no meio de cultura proporciona a iniciação de uma zona meristemática radicular e/ou estimula o

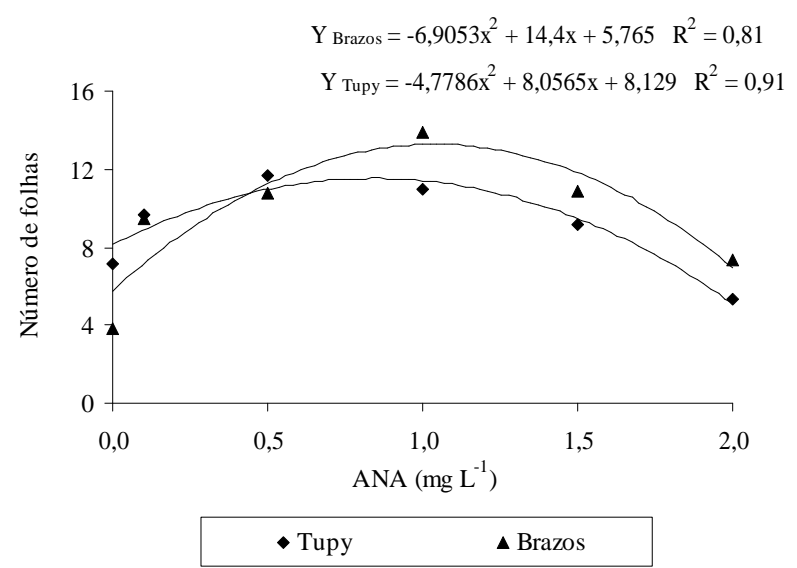

Figura 1B - Número de folhas em plântulas de amoreirapreta, com diferentes concentrações de ANA. UFLA, Lavras, MG, 2006.

desenvolvimento de uma zona radicular existente. Todavia, quando aplicado em concentrações elevadas, impede a formação de raízes. De modo semelhante, Deccetti (2000) observou alto porcentual de enraizamento e maior número de raízes em porta-enxerto de anonácea (Annona glabra), na ausência de regulador de crescimento.

Utilizando-se $0,1 \mathrm{mg} \mathrm{L}^{-1}$ de ANA obteve-se um comportamento linear em relação ao comprimento da maior raiz da cv. Ébano $(1,17)$, sendo que a partir dessa concentração ocorreu uma diminuição no comprimento das mesmas (Figura 3A). Já na ausência da giberelina melhores resultados foram observados para essa variável (Figura 3B). Brum (2001) verificou que, na figueira (Ficus carica L. cv. Roxo de Valinhos), uma relação auxina/citocinina mais alta com 0,1 ou $0,2 \mathrm{mg} \mathrm{L}^{-1}$ de ANA ocasiona menor crescimento de raiz.

Foi verificada a presença de calo em algumas plântulas de amoreira-preta. Dantas et al. (1999) afirmaram que a adição de $0,5 \mathrm{mg} \mathrm{L}^{-1}$ de ANA ao meio de cultura MS favoreceu a formação de calo na base das brotações da cv. Caigangue e que, na ausência dessa auxina, as brotações apresentaram melhor enraizamento. Segundo Grattapaglia \& Machado (1990), a presença da auxina no meio leva à maior formação de calo, comprometendo a formação de raízes.

Como ocorreu interação significativa para o comprimento da parte aérea da amoreira-preta, melhores resultados para a cv. Ébano foram obtidos na ausência de ANA e $8,0 \mathrm{mg} \mathrm{L}^{-1}$ de $\mathrm{GA}_{3}$ (Figura 4A) e, para as cvs. Brazos e Tupy, maiores alturas foram verificadas na suplementação de $1,0 \mathrm{mg} \mathrm{L}^{-1}$ de ANA no meio de cultura (Figura 4B). 


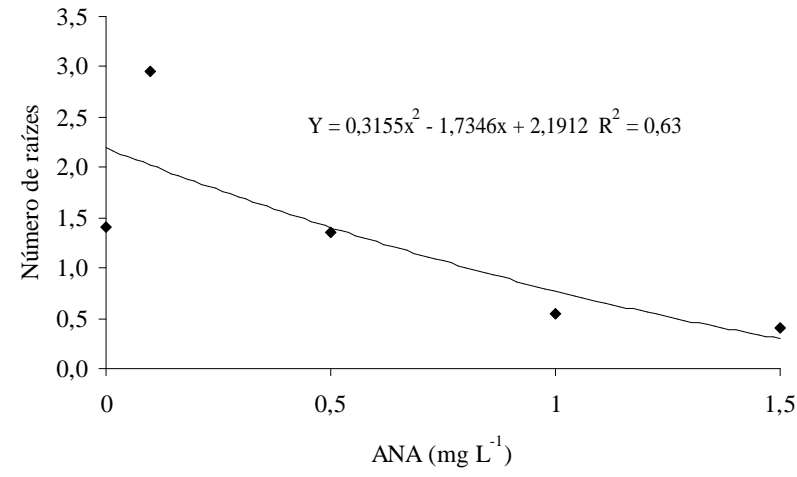

Figura 2 A - Número de raízes em plântulas de amoreirapreta cv. Ébano, com diferentes concentrações de ANA. UFLA, Lavras, MG, 2006.

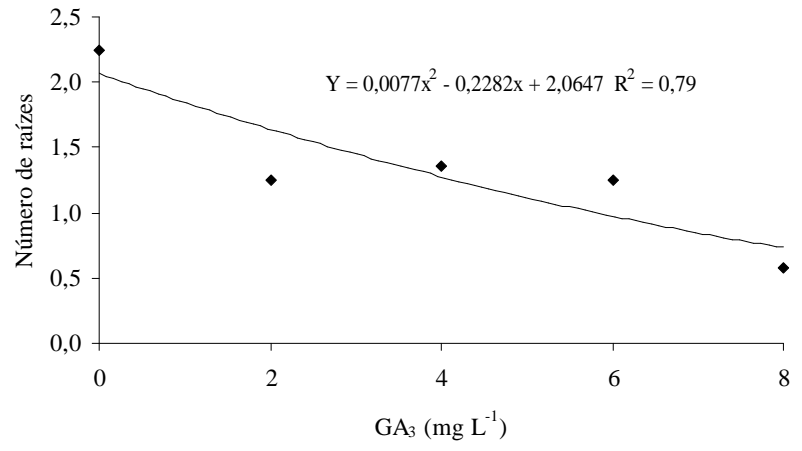

Figura 2B - Número de raízes em plântulas de amoreirapreta cv. Ébano, com diferentes concentrações de $\mathrm{GA}_{3}$. UFLA, Lavras, MG, 2006.

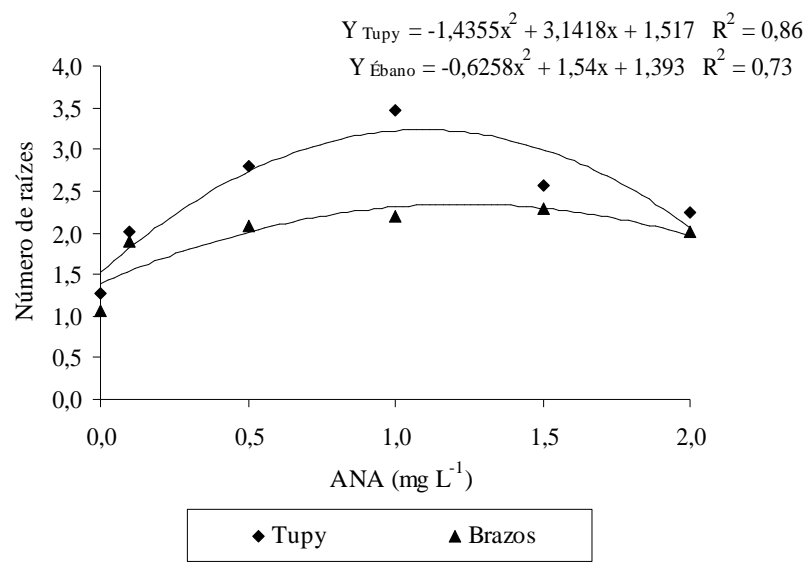

Figura 2C - Número de raízes em plântulas de amoreira-preta, com diferentes concentrações de ANA. UFLA, Lavras, MG, 2006.

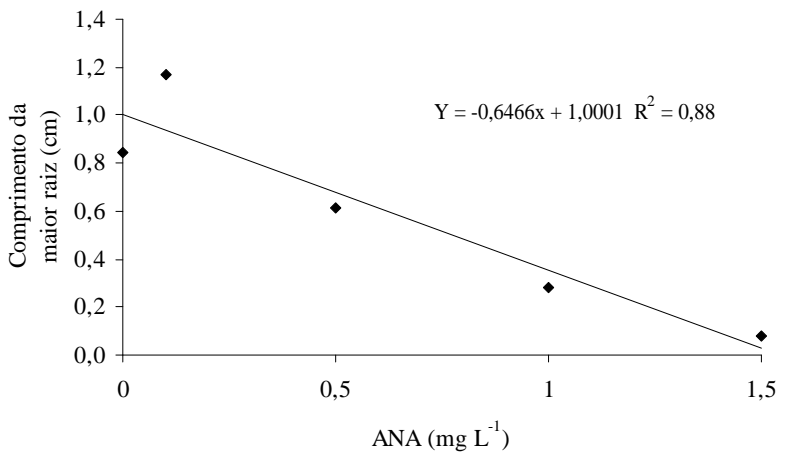

Figura 3A - Comprimento da maior raiz em plântulas de amoreira-preta cv. Ébano, com diferentes concentrações de ANA. UFLA, Lavras, MG, 2006.

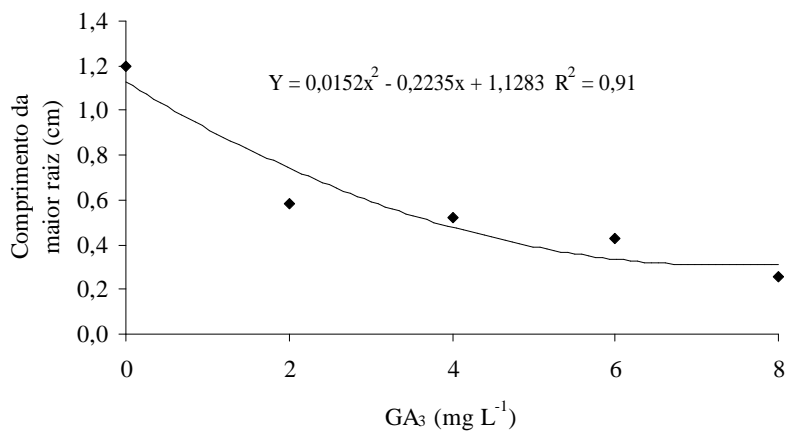

Figura 3B - Comprimento da maior raiz em plântulas de amoreira-preta cv. Ébano, com diferentes concentrações de $\mathrm{GA}_{3}$. UFLA, Lavras, MG, 2006. 
Houve interação significativa para o peso da matéria fresca da parte aérea das cvs. estudadas, onde melhores resultados para a cv. Ébano foram observados na ausência de $\mathrm{GA}_{3}$ e em 0,5 $\mathrm{mg} \mathrm{L}^{-1}$ de ANA (Figura 5A). Com o aumento das concentrações da auxina verificouse um decréscimo de forma quadrática no peso da matéria fresca da cv. Ébano, sendo que o inverso foi observado

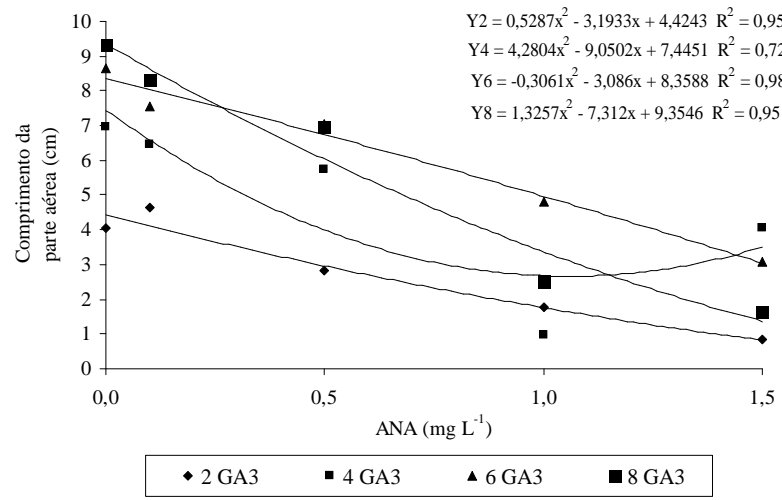

Figura 4 A - Comprimento da parte aérea em plântulas de amoreira-preta cv. Ébano, com diferentes concentrações de GA. UFLA, Lavras, MG, 2006.

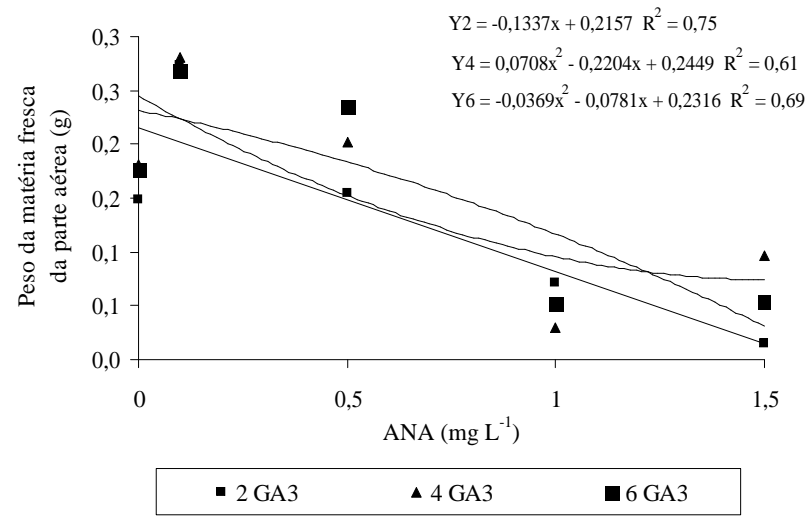

Figura 5 A - Peso da matéria fresca da parte aérea em plântulas de amoreira-preta cv. Ébano, com diferentes concentrações de ANA e GA. UFLA, Lavras, MG, 2006. nas cvs. Brazos e Tupy (Figura 5B). Fráguas (2003) obteve maior peso da matéria fresca da parte aérea na ausência de $\mathrm{GA}_{3}$ e cinetina. Quando se utilizaram as concentrações 2,0; 4,0; 6,0 e 8,0 $\mathrm{mg} \mathrm{L}^{-1}$ de $\mathrm{GA}_{3}$ houve aumento de peso até a concentração de $2,0 \mathrm{mg} \mathrm{L}^{-1}$ de cinetina, ocorrendo em concentrações superiores uma redução no tamanho das plântulas.

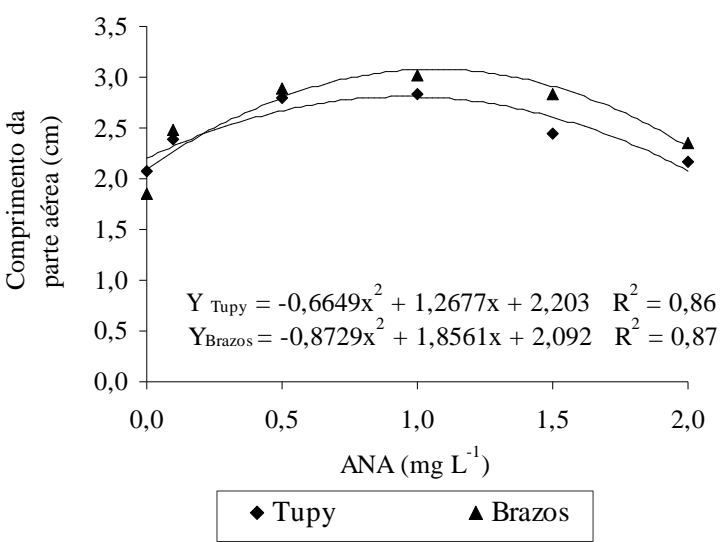

Figura 4B - Comprimento da parte aérea em plântulas de amoreira-preta, com diferentes concentrações de $\mathrm{GA}_{3}$. UFLA, Lavras, MG, 2006.

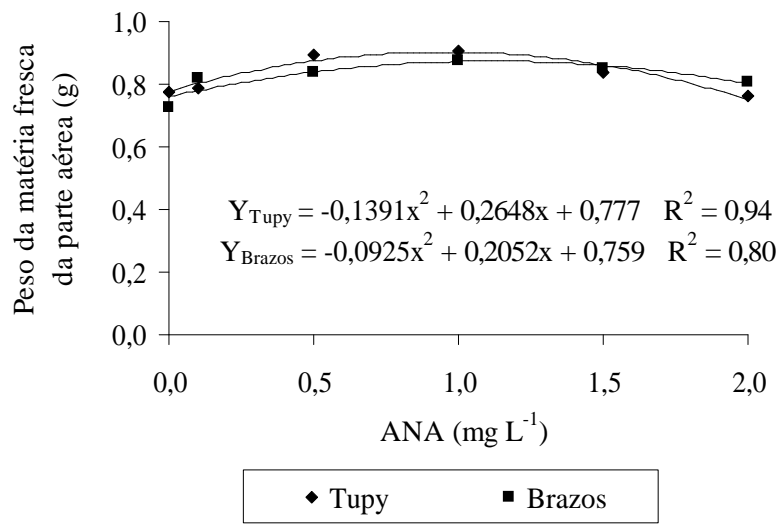

Figura 5B - Peso da matéria fresca da parte aérea em plântulas de amoreira-preta, com diferentes concentrações de ANA. UFLA, Lavras, MG, 2006. 


\section{CONCLUSÕES}

Altas concentrações de $\mathrm{GA}_{3}$ associadas a baixas de ANA promoveram maior comprimento da parte aérea da amoreira-preta cultivar Ébano. Maior comprimento da parte aérea de 'Brazos' foi verificado na presença de $1,0 \mathrm{mg} \mathrm{L}^{-1}$ de ANA.

Verificou-se surgimento de calos na cultivar Ébano em todas as concentrações de $\mathrm{GA}_{3}$ associadas a 0,5-1,5 $\mathrm{mg} \mathrm{L}^{-1}$ de ANA e nas cultivares Tupy e Brazos em todas as concentrações de ANA.

Melhores resultados na micropropagação da amoreira-preta, cultivares Tupy e Ébano, foram obtidos com a adição de $1,0 \mathrm{mg} \mathrm{L}^{-1}$ de ANA e melhores resultados no enraizamento da amoreira-preta cultivar Ébano foram obtidos com baixas concentrações de ANA e na ausência de $\mathrm{GA}_{3}$

\section{REFERÊNCIAS BIBLIOGRÁFICAS}

ANTUNES, L. E. C.; RASEIRA, M. C. B. Aspectos técnicos da cultura da amora-preta. Pelotas: Embrapa Clima Temperado, 2004. (Documentos, 122).

AUGUSTO, C. S. S. Micropropagação da amoreira-preta cv. Brazos. 2001. 115 f. Dissertação (Mestrado em Fitotecnia) - Universidade Federal do Paraná, Curitiba, 2001.

BRUM, G. R. Micropropagação da Figueira (Ficus carica L.) 'Roxo de Valinhos'. 2001. 41 p. Dissertação (Mestrado em Fitotecnia) - Universidade Federal de Lavras, Lavras, 2001.

DANTAS, A. C. M.; CERETTA, M.; FORTES, G. R. L.; COUTINHO, E. F. Enraizamento in vitro da amora-preta (Rubus sp.) cultivar Caigangue. Agropecuária de Clima Temperado, Pelotas, v. 2, n. 2, p. 123-130, 1999.

DECCETTI, S. F. C. Propagação in vitro de Annona glabra L. 2000. 101 p. Dissertação (Mestrado em Fisiologia Vegetal) - Universidade Federal de Lavras, Lavras, 2000.

FERREIRA, D. F. Análises estatísticas por meio do Sisvar para Windows versão 4.0. In: REUNIÃO ANUAL DA REGIÃO BRASILEIRA DA SOCIEDADE INTERNACIONAL DE BIOMETRIA, 45., 2000, São Carlos. Anais... São Carlos: UFSCar. 2000. p. 255-258.

FRÁGUAS, C. B. Micropropagação e aspectos da anatomia foliar da figueira 'Roxo de Valinhos' em diferentes ambientes. 2003. 110 p. Dissertação (Mestrado em Fitotecnia) - Universidade Federal de Lavras, Lavras, 2003.

GRATTAPAGLIA, D.; MACHADO, M. A. Micropropagação. In: TORRES, A. C.; CALDAS, L. S. Técnicas e aplicações de cultura de tecidos de plantas. Brasília, DF: ABCTP/Embrapa-CNPH, 1990. p. 99-169.

KOCHBA, J.; BUTTON, J.; SPIEGEL-ROY, P.; BORNMAN, C. H.; KOCHBA, M. Stimulation of rooting of citrus embryoids by gibberelic acids and adenine sulphate. Annals of Botany, London, v. 38, n. 157, p. 795-802, 1974.

MOKHAMMED, A. I.; BUTENKO, R. G. Cultivar specific features in raspberry clonal micropropagation. Russian Journal of Plant Physiology, Moscow, v. 45, n. 5, p. 692694, 1998.

MURASHIGE, T.; SKOOG, F. A revised medium for rapid growth and bioassays with tobacco tissue cultures. Physiologia Plantarum, Copenhagen, v. 15, p. 473-497, 1962.

OLIGER, P.; PARRAGUEZ, L.; GEBAUER, M.; ARCE, P. Micropropagación y estudos regenerativos in vitro de mora cultivada (Rubus spp.). Ciência e Investigación Agrária, Santiago, v. 22, n. 3, 1995.

PASQUAL, M. Propagação de plantas ornamentais. Lavras: UFLA/FAEPE, 2000. (Textos acadêmicos).

PASQUAL, M.; PEIXOTO, P. H. P.; SANTOS, J. C.; PINTO, J. E. B. P. Propagação "in vitro" da amora-preta (Rubus spp.) cv. Ébano: uso de reguladores de crescimento. Ciência e Agrotecnologia, Lavras, v. 15, n. 3, p. 282-286, 1991.

RASEIRA, M. C. B. A pesquisa com amora-preta no Brasil. In: SIMPÓSIO NACIONAL DO MORANGO, 2.; ENCONTRO DE PEQUENAS FRUTAS E FRUTAS NATIVAS, 1., 2004, Pelotas. Palestras... Pelotas: Embrapa Clima Temperado, 2004. p. 219-223. (Documentos, 124).

TAIZ, L.; ZEIGER, E. Plant physiology. California: Redwood, 1991.

YING, G.; ZHAO, C. M.; JUN, W. On Rubus resources in hunan and fujian provinces. In: INTERNATIONAL CONGRESS ABSTRACT, 23., 1990. Resumes... [S.1.: s.n.], 1990. p. 4014. 